\title{
Microscopy of High Chloride Primary Froth: Non-mixing emulsified water
}

\author{
G. R. D. Elliott*, V. A. Munoz* and R. J. Mikula* \\ *CanmetENERGY, Devon Research Centre, Natural Resources Canada, 1 Oil Patch Drive \\ Devon, Alberta, Canada, T9G 1A8
}

The water chemistry of oil sand ores depends upon the geological formation in which the original oil was intruded. Prehistoric marine environments typically have significantly higher chloride contents than oil sand ores from estuarine locations. Since most of the water used to extract bitumen from the oil sands is recycled, any dissolved ions contributed from the ore will accumulate. Chloride is of particular concern because it can affect the refinery operations (corrosion). During the water based extraction process, a bitumen concentrate known as primary froth is produced with a distribution of emulsified water. The larger emulsion droplets are removed with the recycled process water, while the smaller emulsion droplets reflect a water chemistry of the original geological deposition. As the oil sands mining operation moves from a low chloride ore to a higher chloride ore, the impact of the new water chemistry on the refinery due to the ore is expected to only change gradually as the high chloride from the ore water is mixed with the large volumes of recycle water. This study shows, via direct microscopic observation, that the smaller, more difficult to remove water droplets in the bitumen have the highest chloride concentrations, reflective of the original ore water, and not of a well mixed system including the recycle water. This means that the impact on the upgrader and refinery (due to chloride) can be immediate, rather than gradually occurring over a number of years as it would be predicted if the water in the ore and the recycled water were a well mixed system. A method was developed to measure the size of the droplets and chloride concentration in a primary froth using a combination of cryo-scanning electron microscopy and elemental mapping by $\mathrm{x}$-ray spectroscopy analysis.

The cryogenic preparation of the high chlorine primary froth was conducted from a known high chlorine ore. Samples of primary froth emulsions were plunged frozen in liquid nitrogen slush, sublimed for 30 minutes at $-65^{\circ} \mathrm{C}$, and gold coated. A long sublimation period was required to allow the ice from the water droplets to be sublimed off leaving the precipitated chloride composite crystals. Once sublimed and gold coated the samples were imaged.

The morphology and x-ray spectroscopy analysis of the fractured primary froth showed unique distribution of water droplet size and precipitation of the chloride ions into compound crystals within the sublimed water droplets. The distribution of the water droplets that did not readily coalesce in the primary froth range from 1 to $110 \mu \mathrm{m}$ in diameter with a mean diameter of $6.87 \pm 0.41 \mu \mathrm{m}(\mathrm{n}=858)$. The droplets with high chloride concentrations tended to precipitate with potassium the most, then calcium and least of all sodium. The two morphologies of crystals that were found when the water was sublimed off were either: type 1 - a solid composite crystal with solids in small water droplets (Figure 1 - Type 1); or type 2 - a diffuse network of crystals with solids in large water droplets (Figure 1 - Type 2). When the precipitated crystal composites were analyzed by $\mathrm{x}$-ray spectroscopy the chloride was associated the most with potassium. By the process of elemental mapping by x-ray spectroscopy a map of chloride, potassium and calcium can be generated (Figure 2A,B). The elemental mapping of the primary froth showed the chloride (red) and potassium (blue) were associated with the emulsified water droplet while the carbon (green) had very little dissolved ions. 


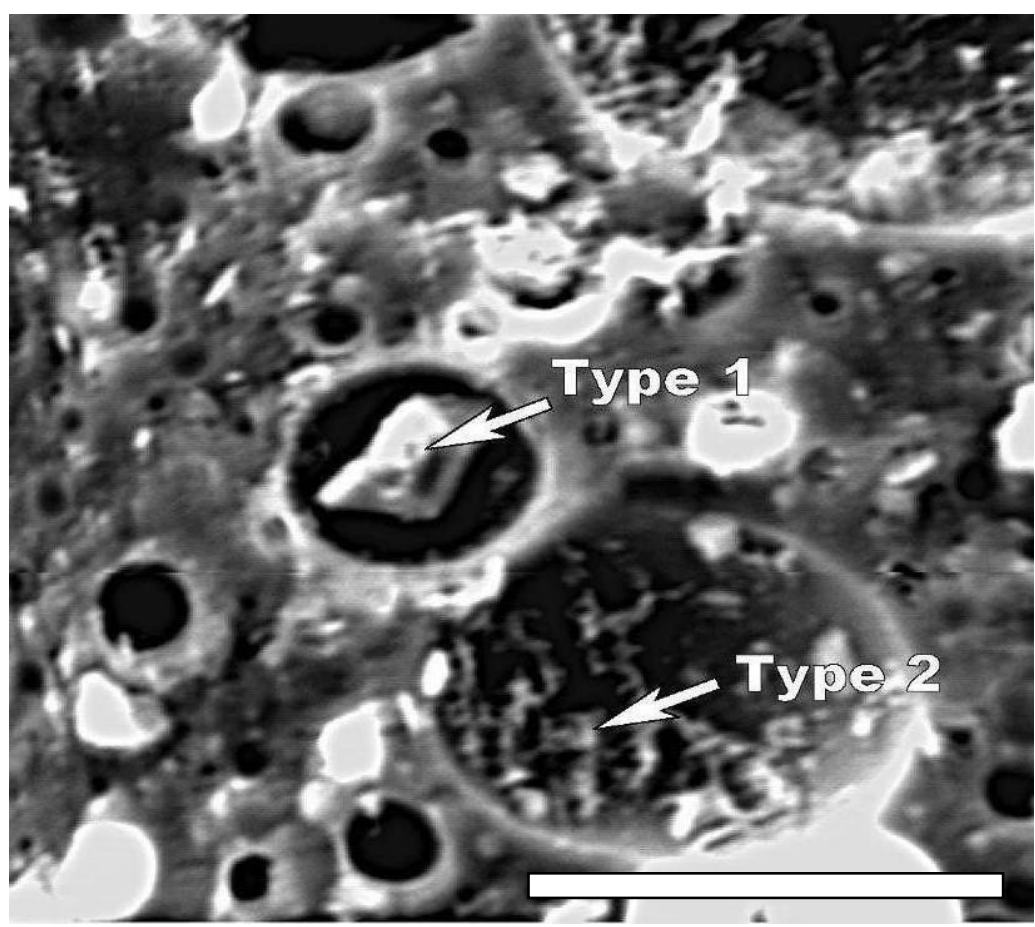

Figure 1. Two precipitate morphologies found in sublimed primary froth emulsified water droplets. Scale bar, $60 \mu \mathrm{m}$.

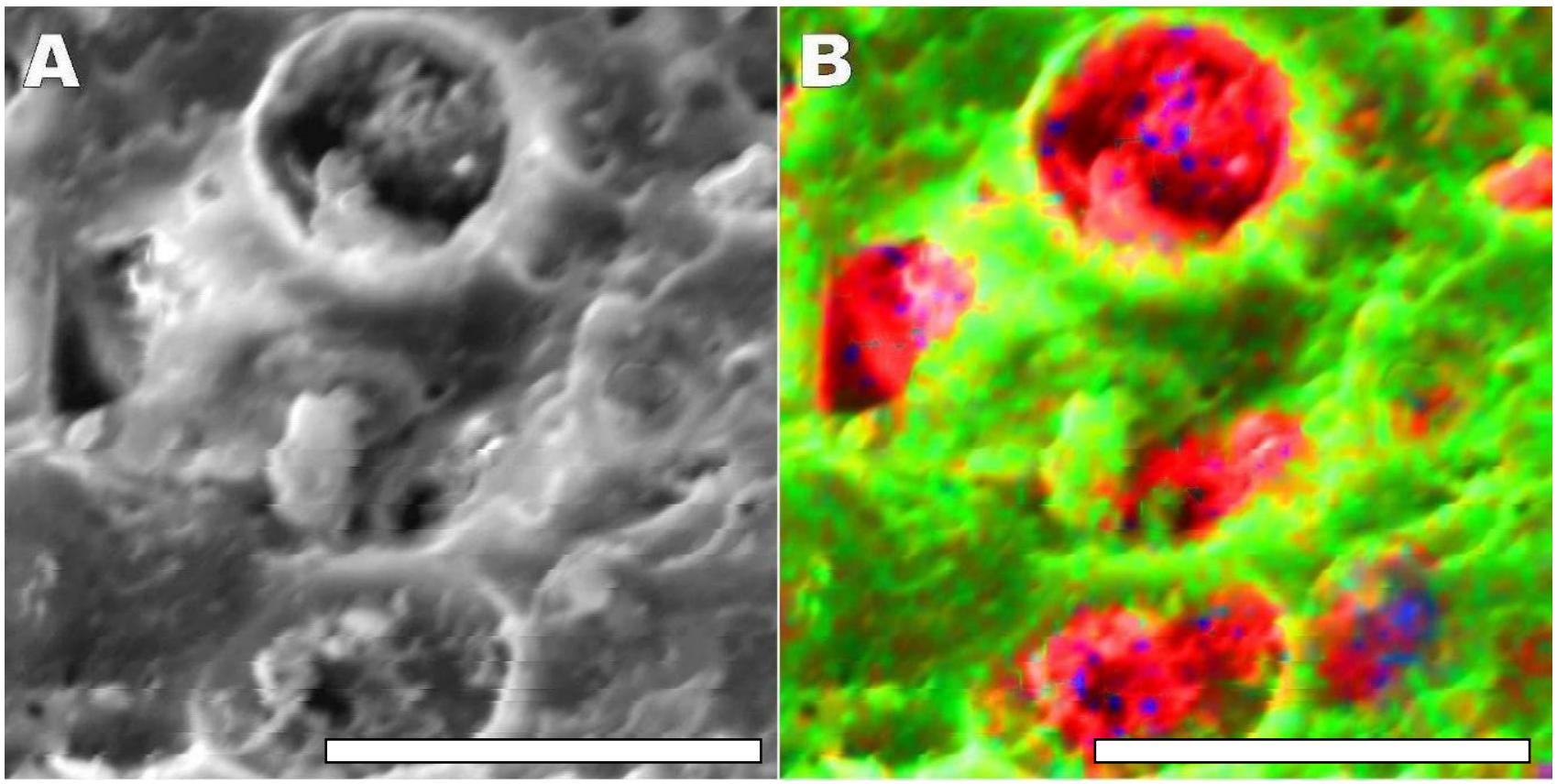

Figure 2. X-ray spectroscopy elemental map of fractured and sublimed primary froth emulsified water droplets. A) Scanning electron image of a fractured primary froth sample showing the precipitates from the sublimed emulsified water droplets. Scale bar, $40 \mu \mathrm{m}$. B) X-ray spectroscopy elemental map showing the distribution of chloride (red), potassium (blue) and background carbon (green). Scale bar, $40 \mu \mathrm{m}$. 